\title{
MEMÓRIA, TRAUMA E IDENTIDADE: TRAJETÓRIAS NA IRMANDADE DE NARCÓTICOS ANÔNIMOS
}

\author{
MEMORIA, TRAUMA E IDENTIDAD: TRAYECTORIAS EN LA ORGANIZACIÓN \\ COMUNITARIA DE NARCÓTICOS ANÓNIMOS
}

\author{
MEMORY, TRAUMA AND IDENTITY: TRAJECTORIES IN THE FELLOWSHIP OF \\ NARCOTICS ANONYMOUS
}

\author{
Rodolfo Ferreira da SILVA ${ }^{1}$
}

RESUMO: O presente trabalho tem por objetivo investigar como os membros da irmandade de Narcóticos Anônimos lidam com a questão da memória, do trauma e do tratamento. O trauma é ressignificado, proporcionando a reconstrução das identidades sociais dos membros, através de um processo no qual a chave para a recuperação, segundo essa visão, passa pela narrativa e pelo sentimento de pertencimento e identificação com o grupo.

PALAVRAS-CHAVE: Narcóticos anônimos (NA). Dependência química. Memória. Trauma.

RESUMEN: El presente trabajo tiene por objetivo investigar cómo los miembros de la organización comunitaria de Narcóticos Anónimos se ocupan de la cuestión de la memoria, del trauma y del tratamento. El trauma es resignificado, proporcionando la reconstrucción de las identidades sociales de los miembros, a través de un proceso donde la clave para la recuperación, según esa visión, pasa por la narrativa y el sentimiento de pertenencia e identificación con el grupo.

PALABRAS CLAVE: Narcóticos anónimos (NA). Dependencia química. Memoria. Trauma.

ABSTRACT: The purpose of this paper is to investigate how members of the fellowship of Narcotics Anonymous deal with the issue of memory, trauma and treatment. The trauma is resignified, providing the reconstruction of the social identities of the members, through a process where the key to recovery, according to this vision, passes through the narrative and the feeling of belonging and identification with the group.

KEYWORDS: Narcotics Anonymous (NA). Chemical dependency. Memory. Trauma.

${ }^{1}$ Universidade do Estado do Rio de Janeiro (UERJ), Rio de Janeiro - Brasil. Mestrando em Ciências Sociais. ORCID: https://orcid.org/0000-0002-2126-3091. E-mail: rodolfoferreirasilva1974@gmail.com. 


\section{Introdução}

São 19 h 30 min. Numa sala anexa a uma Igreja Católica na cidade do Rio de Janeiro, um grupo de cerca de 30 pessoas se reúne. A sala é espaçosa e confortável. As cadeiras plásticas são dispostas de maneira que formem um círculo. Numa mesa, vemos uma série de panfletos coloridos e livros sobre uma toalha de mesa azul. Uma sineta toca, anunciando o início de mais uma reunião de Narcóticos Anônimos. Após um instante de silêncio, o grupo em uníssono repete a 'Oração da Serenidade'2, seguida das apresentações. Após a oração, o secretário, sentando-se atrás da mesa, pergunta se há alguém assistindo aquela reunião pela primeira vez. É nesse momento que todos se voltam para um rapaz, na casa dos vinte anos, com semblante cansado e desalinhado. O rapaz levanta a mão e diz o seu primeiro nome, no que é prontamente respondido pelo grupo mais uma vez em uníssono: 'Oi, Ronaldo ${ }^{3}$, seja bem-vindo!' O secretário inicia os depoimentos após a leitura de um dos folhetos - Bem-vindo a Narcóticos Anônimos (1993) -, ressaltando que há um 'recém-chegado' no grupo. Todos os depoimentos que se sucedem caminham no sentido de, como alerta o secretário, ele mesmo também um membro, 'levar a quinta tradição'.

Segundo a quinta tradição "cada grupo tem apenas um único propósito primordial, levar a mensagem ao adicto que ainda sofre" (NARCOTICS ANONYMOUS WORLD SERVICES, 2015, p. 75). Nesse sentido, todos os depoimentos se dirigem ao Ronaldo, que ouve com atenção as histórias dos membros mais antigos, que vão se sucedendo no mesmo sentido, revelando a face obscura do seu uso abusivo de drogas (ORGANIZAÇÃO MUNDIAL DE SAÚDE, 1993, p. 69-82), o ‘fundo de poço' e a possibilidade de recuperação em Narcóticos Anônimos.

Após uma hora de depoimentos, o secretário faz a leitura de um trecho do texto básico de Narcóticos Anônimos e pergunta se há alguém naquela sala que gostaria de fazer parte de NA, bastando para tanto levantar o braço e dizer o seu primeiro nome. Ronaldo, com as mãos trêmulas e a voz embargada, num misto de emoção, medo e esperança, levanta o braço, diz o seu primeiro nome, no que é prontamente respondido por muitos aplausos. Ele teria sete minutos como os outros para se manifestar, mas a emoção o impede. Recebe então um chaveiro branco que simboliza o seu 'ingresso em NA', alguns folhetos e números de telefone para ligar caso sinta 'vontade de usar'.

2 "Deus, conceda-me serenidade para aceitar as coisas que eu não posso modificar, coragem para modificar aquelas que eu posso e sabedoria para reconhecer a diferença".

${ }^{3}$ Os nomes foram trocados para preservar a identidade dos membros. 
A descrição acima é parte de uma reunião de Narcóticos Anônimos que tive a oportunidade de assistir e que à época despertou profundo interesse sobre aquilo que acabara de presenciar.

O 'ingresso', a entrada no e para o grupo parece operar como um divisor de águas, com carga simbólica muito semelhante aos rituais de conversão religiosa (RAMBO, 1993), sobretudo das Igrejas de matriz protestante. As histórias ali contadas são diversas em conteúdo, mas muito parecidas na forma. Há um sentido que se constrói para a experiência com uso de drogas que passa necessariamente pela incapacidade de o levar a um bom termo. Dito de outra forma, a incapacidade de funcionar socialmente, entendida no contexto de uma sociedade capitalista e hedonista.

Os traumas ali narrados são dotados de forte carga emocional. No entanto, parecem funcionar como catalizadores de um sentimento de 'pertencimento' que aglutina e liberta. A palavra, nesse sentido, conecta o indivíduo com o grupo e, por extensão, consigo mesmo. 'Você não está mais sozinho'; 'Estamos juntos'; 'Continue voltando que funciona', foram frases ditas a Ronaldo após a reunião e a decisão do mesmo de ingressar. Também é interessante notar o aparente paradoxo de algumas falas, articuladas ao primeiro passo. Para os membros de Narcóticos Anônimos, a admissão da 'derrota' constitui o primeiro passo no caminho da 'recuperação'. Ou seja, o tratamento, nessa visão, só se torna possível no momento que o indivíduo resolve admitir não conseguir mais 'gerenciar' a própria vida, entendida aqui como a capacidade de trabalhar e se relacionar socialmente, usando drogas ao mesmo tempo. O tratamento, portanto, só têm efeito na medida em que ele continue a frequentar as reuniões de forma sistemática e disciplinada e 'evite a primeira dose'. Dessa forma, percebemos que o 'ingresso', na verdade, não é apenas um 'momento', mas um 'processo' que deve ser seguido pelo indivíduo como forma de se integrar e se inserir naquilo que os membros chamam de recuperação. Assim, frequentar as reuniões diariamente durante 90 dias, falar com membros mais experientes, pedir auxílio quando necessário, 'partilhar' nas reuniões de forma 'honesta', são algumas dessas sugestões que são feitas aos 'recém-chegados'. Agindo assim, dizem, poderão então "parar de usar, perder o desejo e encontrar uma nova maneira de viver"4.

O presente trabalho tem por objetivo perceber de que maneira os membros de Narcóticos Anônimos lidam com a questão da construção da memória, do trauma e do tratamento em NA. Durante nossa pesquisa, realizamos entrevistas com membros de Narcóticos Anônimos de um grupo na Zona Sul da cidade do Rio de Janeiro, lócus de nossa atuação. A entrevista reproduzida

${ }^{4}$ Frase ouvida com frequência nas reuniões de Narcóticos Anônimos. 
aqui, foi organizada de maneira semiestruturada. Foram feitas perguntas sobre momentos diversos da vida, como a infância, o começo do uso de drogas, o "fundo de poço', o ingresso em Narcóticos Anônimos e o tratamento. Para tanto, nos dispusemos a ouvir sem um limite de tempo pré-estabelecido. A entrevista durou em média, uma hora. Assumimos o compromisso de preservar o anonimato e por isso o nome foi trocado.

Foram muitas horas de trocas intensas e reveladoras, na entrevista e no trabalho de campo que nos possibilitaram perceber em que medida opera o que os Narcóticos Anônimos designam como o 'caráter terapêutico de um adicto ajudando outro', praticando o que em psicologia se denomina a 'teoria do espelho', segundo a qual, enxergando no outro o seu próprio problema, ficaria mais fácil à reabilitação do indivíduo.

Por fim, gostaríamos de enfatizar que este trabalho não trata ou pretende tratar da natureza da dependência química e/ou da eficácia do tratamento em Narcóticos Anônimos. Nosso interesse baseia-se na percepção que os membros têm do programa, como eles vão reinterpretar a própria trajetória e, sobretudo os traumas provenientes do uso de drogas, a partir da cosmovisão de mundo de Narcóticos Anônimos.

\section{Memória e Identidade}

Podemos pensar a memória como a capacidade de armazenar fatos ou informações vividas no passado ou como reminiscências do passado. Os estudos relativos à memória se inserem num vasto campo de análise, sobretudo nas ciências humanas, atuando de maneira transversal e/ou articulada na Sociologia, Filosofia, Psicologia, Antropologia, etc.

A partir dos anos 80, os estudos sobre a memória coletiva cresceram em interesse, ganhando destaque as análises de Maurice Halbwachs. Dessa forma, aprofunda-se o debate sobre a questão indivíduo-sociedade, presente nas Ciências Sociais, onde sobressai a noção da memória como um fenômeno eminentemente coletivo. A memória então seria um fenômeno social, coletivo, constituindo-se a partir das relações entre os indivíduos e grupos. A memória individual não deixa de existir, mas está enraizada em diferentes contextos nos quais os indivíduos se inserem com diferentes participantes. Isso permite a transposição de uma memória individual para uma memória coletiva. "Mas nossas lembranças permanecem coletivas, e elas nos são lembradas pelos outros, mesmo que se trate de acontecimentos nos quais só nós estivemos envolvidos, e com objetos que só nos vimos. É porque, em realidade, nunca estamos sós" (HALBWACHS, 1968, p. 24). Assim, as lembranças do passado só podem 
existir a partir dos 'quadros sociais da memória'. Quando diz que nunca estamos sós, o que ele quer dizer é que nossa percepção de mundo e a formação das nossas memórias estão impregnadas de nossas experiências sociais anteriores. Ainda que me encontre aparentemente só em um local qualquer, as minhas memórias que se formarão sobre este lugar estarão informadas pelas minhas experiências anteriores, sejam elas transmitidas através de outros ou assimiladas por um filme, um livro, uma música ou qualquer outra informação do local. A linguagem assim representa um importante marcador, uma vez que é algo anterior a nossa existência, informada e apreendida no processo de socialização.

No entanto, para que esta memória se afirme e que não haja um esquecimento, que se dá pelo desapego de um grupo do qual fizemos parte, é necessário que se insira nos quadros de uma 'comunidade afetiva'.

Não é suficiente reconstruir peça por peça a imagem de um acontecimento passado para se obter uma lembrança. É necessário que esta reconstrução se opere a partir de dados ou noções comuns que se encontram tanto no nosso espírito com no dos outros, porque elas passam incessantemente desses para aquele e reciprocamente, o que só é possível se fizeram e continuam a fazer parte de uma mesma sociedade. Somente assim podemos compreender que uma lembrança possa ser ao mesmo tempo reconhecida e reconstruída" (HALBWACHS, 1968, p 34).

Assim, a identidade coletiva de um grupo também se constrói através de um processo que é, ao mesmo tempo, político e social. Tal processo define, por exemplo, grupos que serão reconhecidos como também aqueles que serão marginalizados.

Desde a segunda Revolução Industrial, na segunda metade do século XIX, o uso de drogas vai gradativamente saindo da esfera privada e entrando na esfera social. A preocupação com o consumo dessas substâncias deve-se em grande medida à necessidade de ampliação de uma mão de obra cada vez mais demandada em função dos avanços científicos e tecnológicos (fordismo e taylorismo) do processo de industrialização, com também o ascetismo de matriz protestante, transformando esta questão num debate moral. Nesse quadro, o uso de substâncias psicoativas e do álcool transforma-se num problema social, na medida em que pode ser percebido como um entrave ao próprio desenvolvimento do capitalismo, bem como numa questão de ordem moral, que atacava diretamente 'um estilo de vida', notadamente ocidental e que teve seu início marcadamente nos EUA.

Os usuários de drogas então são excluídos e marginalizados, dificultando ainda mais o acesso aos programas de tratamentos. Em 1953, William Burroughs narra suas experiências no submundo das drogas nos anos 1940/50. 
Droga pesada - junk - é uma equação celular que ensina ao usuário (junky) verdades de validade universal. Aprendi muito usando junk: vi a vida sendo medida em conta-gotas com solução de morfina. Senti a privação agônica da droga - a chamada "fissura" - e o alívio prazeroso quando as células sedentas de junk bebiam da agulha. É possível que todo prazer seja apenas alívio. Aprendi o estoicismo celular que a droga ensina ao usuário. Vi uma cela repleta de junkies fissurados, silentes e imóveis em suas misérias estanques. Eles sabiam o quanto era inútil reclamar ou se mover. Sabiam que ninguém ali podia ajudar ninguém. Não há nenhum recurso, nenhum segredo que alguém possua e possa te oferecer" (BURROUGHS, 2013, p. 18-19).

Eram tempos de criminalização e punição. Sobre essa situação, Jimmy K., um dos fundadores de Narcóticos Anônimos, nos diz que: "Naquele período nos Estados Unidos, muito poucos adictos tiveram efetivamente a escolha como nós temos hoje no programa de Narcóticos Anônimos" (NARCOTICS ANONYMOUS WORLD SERVICES, 2002, p. 16).

$\mathrm{Na}$ medida em que uso abusivo de drogas passa a constituir-se numa questão de saúde pública, ou seja, é reconhecido socialmente como doença, as alternativas para o tratamento se diversificam. Narcóticos Anônimos, que adapta o seu 'programa de recuperação' dos Alcoólicos Anônimos, funciona assim, como uma 'comunidade afetiva', lugar de memória para os membros que, a partir do ingresso, reinterpretam a sua trajetória e, consequentemente, a sua identidade social. As lembranças aqui funcionam como catalizadoras de uma nova identidade, forjadas pela cosmovisão de mundo de NA. Lembrando e 'partilhando' sobre o passado, o membro se reconstrói enquanto indivíduo e membro de um grupo.

O sentido de continuidade e permanência presente em um indivíduo ou grupo social ao longo do tempo depende tanto do que é lembrado, quanto o que é lembrado depende da identidade de quem lembra. Da mesma forma que a identidade, a memória também deixou de ser pensada como um atributo estritamente individual, passando a ser considerada como parte de um processo social em que aspectos da psique se encontram interligados a determinantes sociais. A memória deixou, portanto, de ser considerada como fenômeno individual, passando a elemento constitutivo do processo de construção de identidades coletivas (SANTOS, 1998, p. 160).

Por meio da memória, o grupo assenta suas raízes no passado. Essas memórias conferem estabilidade e materializam o modo de vida do grupo. No caso de Narcóticos Anônimos, a histórias individuais são, com o passar do tempo, incorporadas inclusive por uma linguagem específica, um ritual próprio, que conferem unidade e identidade ao grupo, num sentimento de pertencimento que, na maior parte das vezes, contrasta com a noção de 'despertencimento', de indivíduo 'deslocado' da modernidade. Este 'despertencimento', sentimento comum entre os membros, apareceu na entrevista como um profundo desconforto frente às expectativas demandadas pela sociedade moderna. Como veremos adiante, esta pode ser a base sobre a qual 
se assentam os traumas provocados pelo uso abusivo de drogas, com também o processo de recuperação.

\section{Memória e Trauma}

O trauma pode ser definido como resultado de uma situação marcante e violenta, inesperada e que traz consigo a incapacidade de lidar, ao menos de maneira imediata, de reconhecê-lo com tal. O trauma muitas vezes silencia e não encontra formas de representação suficientemente 'reais'. O realismo, nesse sentido, pode paradoxalmente servir como forma de negação do próprio evento, diante do horror provocado pela representação dele. A narração de histórias traumáticas não é linear, existem bloqueios que podem provocar alternâncias e descontinuidades, lapsos espaço-temporais.

Para Hartman (2000), há a necessidade de uma discussão sobre as formas de representações de traumas. A 'espetacularização' do trauma pela mídia, a 'rotinização' de imagens extremas, acaba provocando uma dessensibilização, levando à diminuição da empatia e a necessidade constante de contato com esse tipo de visão. Nesse sentido, surgiriam questões sobre os limites da representação. Como representar um evento extremo? Diante de dessensibilização provocada pela enxurrada de imagens violentas a que somos submetidos diariamente, como abordar, por exemplo, a questão do Holocausto e a sua representação sem que se incorra no erro de transformá-lo em simulacro do evento originário?

[...] testemunhos em vídeo restauram a 'memória profunda', tanto quanto detalhes informativos específicos do terror e sofrimento (...) O meio vídeovisual não existe para servir à narrativa, mas para corporificar o sobrevivente, substituindo fotos nazistas degradantes e às vezes injuriosas que, até recentemente, eram o que haviam de mais comum nos museus do Holocausto (HARTMAN, 2000, p. 207-235).

Assim, percebe na arte uma forma potente de lidar com a questão do Holocausto e a representação desse tipo de trauma. Aponta Paul Celan como 'o maior poeta em língua alemã nos anos do pós-guerra'. Para ele, a ausência, marca do estilo de Celan, é uma forma de 'testemunho' daquilo que não encontra formas de representações possíveis de estar à altura de tanto terror.

É nesse sentido que caminha também a análise de Márcio Seligmann-Silva (2000). Para ele, o historiador da Shoa se encontra numa encruzilhada entre a necessidade e a incapacidade descrever um evento tão brutal. "Como representar algo que vai além da nossa capacidade de 
imaginar e representar?" (SELIGMANN-SILVA, 2000, p. 79). Segundo ele, Hartman coloca uma questão que desloca a forma da representatividade desta realidade para o questionamento se ela deveria ser experienciada. O trauma, assim, é uma "ferida na memória" (SELIGMANNSILVA, 2000, p. 84).

Em Narcóticos Anônimos, narrar o trauma, entrando em contato com ele através do testemunho em grupos é entendido como uma forma de minimizar os males provocados pelo trauma. Como pude ouvir por diversas vezes, em minha pesquisa de campo: 'dor partilhada é dor diminuída'.

Ordem, hierarquia e controle são valores políticos incorporados pela prática médica que, durante muito tempo estigmatizaram e marginalizaram dependentes químicos, deixando-os 'sem voz'. Essa visão obstaculizou o acesso a políticas públicas de tratamento que diferissem da internação em sanatórios. Alcoólicos Anônimos e posteriormente, Narcóticos Anônimos, surgem como alternativas, onde as memórias traumáticas do uso abusivo de drogas e mais, as raízes desse sentimento de 'despertecimento' da sociedade moderna como um todo, pudessem aflorar, possibilitando um processo de reconstrução de identidades 'perdidas'. As identidades individuais, assim, se reconstroem coletivamente num processo dialético, onde o grupo auxilia o membro que ajuda o grupo.

\section{A História de Ana}

Meu nome é Ana, tenho 51 anos e estou em abstinência há 04 anos, 05 meses e dez dias. Eu nasci no Flamengo, na Rua Dois de dezembro e este bairro é muito significativo. A minha família quando veio do Nordeste veio morar no Flamengo. Após quatro anos de casados, meu pai, que era escriturário do Banco do Brasil, recebeu uma proposta de irmos para Brasília. Morávamos numa 'sala e quarto', eu, meus pais e meus dois irmãos. Em Brasília, meu pai ganhou um apartamento funcional e começou a ter um projeto de carreira. Meu pai era um homem muito esforçado, uma inspiração pra mim! Num dado momento foi pai e mãe da gente, pois minha mãe odiou Brasília que, em 1974, não tinha nada. Fomos morar num apartamento funcional de 03 quartos e meu pai comprou um carrinho. Em Brasília eu faço parte daquela geração de "jovens de fora" e que eram um tanto quanto ociosos. Começamos a fazer cultura lá. Saindo da ditadura, todo mundo hippie, sexo livre, Brasília, disco voador, fumando muita maconha. 
Eu comecei a experimentar drogas com 14 anos. Namorava um menino que tinha uma Harley. Eu fazia parte da turminha dos 'doidões'. Fazíamos parte do grupo dos 'marginais'. Com 14 anos eu comecei a 'dar defeito'. Meus irmãos já usavam. No meu caso, foi muito mais difícil pro meu pai porque eu era filha mulher. Havia o medo de gravidez. Minha mãe havia sido mãe solteira.

Meu pai começou a andar atrás de mim. Começamos a ter uma relação muito complicada. Primeiro experimentei lança-perfume. Antes eu já havia fumado cigarro. Meu pai achou na minha bolsa, eu tinha 10 anos. Ele me deu uma surra 'homérica'. Estudava em colégio de freira. Ser funcionário público nessa época em Brasília proporcionava muito conforto. A minha transgressão começou com cigarro, namorados, etc. Eu me sinto uma adolescente que 'delinquiu'. Só fui experimentar cocaína com 16 anos. Antes, fumava maconha. Não gostava muito de usar, mas usava.

'O que eu tinha de muito forte era muita revolta. Eu tinha muito desconforto e que eu sabia que eu já tinha. Eu percebia que eu tinha uma percepção diferente'. Eu era muito boa em português e redação. 'Era bem emocional a minha forma de me relacionar com as pessoas. Quando eu era encaminhada para conversar com as psicólogas, orientadoras do colégio eu gostava. Eu sentia que eu era uma pessoa diferente'.

Meu pai vivia andando atrás de mim. Eu roubava motos e carros. Meu pai começou a andar com a polícia atrás de mim. Me levou ao IML para descobrir que eu não era mais virgem e processou meu namoradinho. Naquele momento começamos a medir força. Quanto mais não ele me dizia mais 'insanidades' eu cometia. Ele me botou no juizado de menores. Ele tinha porte de armas e eu comecei a roubar o revólver do meu pai para culpá-lo legalmente. Ele me batia. Foi um embate bem complicado. Meu pai queria me proteger, mas eu não via dessa forma. Ele alugou um apartamento aqui no Rio e me mandou pra cá junto com a minha mãe.

'O divisor de águas quando eu e minha família percebemos que se tratava de uma questão de saúde e não legal', foi quando aos 15 anos eu vim de Brasília para o Rio de carona. Eu e outra menina ficamos num apartamento do meu pai em Cabo Frio. Eu arrombei o apartamento e já conhecia uns 'malucos' de Cabo Frio e o apartamento em poucos dias ficou cheio de 'homens' fumando maconha e usando cocaína. Eu ainda não me drogava pesado. Ali eu fiquei assustada comigo!

O porteiro ligou pro meu pai, ele tirou licença, alugou um carro e me pegou na praia! Eu fui levada direto para a Pensão Margarida de Emergências Psiquiátricas. Foi a maneira que eu meu pai encontrou de 'me proteger de mim mesma'. Hoje eu vejo dessa forma. Eu cedi. Eu sempre cedia. 'Eu sentia que havia alguma coisa de muito diferente. Eu não conseguia mais me 
controlar. Eu tinha alguma coisa diferente'. Depois eu fiquei sabendo que eu corri um risco muito grande de ser institucionalizada. Naquela época muitos jovens foram. Eu tive diagnóstico de esquizofrenia, mas isso não convenceu meus pais. Eu não tinha o perfil do 'louco do senso comum', mas meus pais viam em mim uma pessoa muito descompensada. Eu fiquei 12 anos. Minha mãe me tirou e ficamos morando no Rio, num apartamento próprio que meu pai comprou. 'Meu pai era o herói da família'. Em Rondônia, meu pai foi seringueiro. Com isso tudo, fez faculdade e adquiriu um patrimônio.

Minha 'progressão' continuou no Rio. Em Brasília havia discursos filosóficos. Aqui no Rio não, era morro e tráfico. Aqui eu conheci a cocaína com um menino, filho de um porteiro aqui do Flamengo, que se tornou um grande assaltante e ficou preso em Bangu. E tinha também o Lama's. Ali tinha uma coisa de glamour, de papo intelectual. Eu cheirava dentro do banheiro do Lama’s, na Praça São Salvador, frequentava a Galeria Alasca, conheci o pessoal do teatro. Eu nunca gostei muito de maconha. Eu admirava quem tinha uma produção cultural.

Com 16 anos eu queria estudar e não conseguia. 'Eu tentava mais não conseguia mais funcionar'. A medicina não tinha muito recurso. Eu comecei a me relacionar com homens bens mais velhos e traficantes de classe média. Eu morei com um traficante conhecido de Cabo Frio, comecei cheirar todo dia. Eu pedi ajuda a um advogado quando eu e o traficante fomos presos. Eu fui solta, mas ele ficou preso. Acabei me relacionando com o advogado, que acabou virando traficante. Começamos a comprar cocaína em Acari pra revender em Saquarema. Eu não ia um dia a praia. Ficava dias trancada me escondendo do sol, não transpirava, não comia. Foram 03 anos usando muita cocaína. A ficha caiu quando eu raspei os saquinhos de cocaína pra cheirar mais. Consegui fazer uma carreira muito fina. Ele soprou a carreira, disse que eu estava ficando louca. Eu o agredi e bati nele. Dei um soco no nariz dele que começou a sangrar. Eu batia no cachorro dele. A minha referência de revolta era que o meu pai me batia. Eu fui extremamente agressiva. Naquela noite eu peguei as minhas coisas e pedi para os meus pais me internarem naquela clínica.

Nessa mesma noite, eu estava no Lama’s e conheci uma senhora. Ela me disse que a minha história era muito parecida com a da sua filha, que acabara de sair de uma clínica chamada Vila Serena. Ela disse pra eu dormir na casa dela e conversar com a filha dela. Ainda não existia Narcóticos Anônimos, era Toxicômanos Anônimos, em 1986. Eu conversei com a filha dela e fui internada em Vila Serena. Foram 40 dias. O que nós escutamos mudou as nossas vidas. Lá escutamos pela primeira vez sobre dependência química e alcoolismo. Isso explicava como eu 'era uma pessoa muito diferente. Isso explicava minha tolerância física e porque eu não terminava nada que eu começava'. Descobri que era uma 'doença emocional'. Que existia 
um recurso que eram os 'grupos de ajuda mútua'. Eu ingressei no Grupo de Apoio aos Toxicômanos Anônimos (GATA). Eu fiquei apaixonada!

‘A mudança foi completa, visceral' Eu não conseguia sair da sétima série. Aos 19 anos eu fui fazer um supletivo, tirei minha carteira de motorista, fiz tratamento dentário, fui ao ginecologista. 'Era como se a partir daquele momento mudasse toda minha perspectiva, a minha forma de me relacionar com a vida'. Todo aquele desejo de ser uma jovem comum começou a ser possível. Era como seu tivesse 'nascido aos 19 anos de idade'. Tinha muita coisa que eu não sabia fazer. Há muitos anos eu não acordava pela manhã. Aí iniciou um processo que eu compreendo de 'despertar espiritual'. Levou muitos anos pra que eu tivesse um despertar pra vida que eu jamais havia compreendido. 'Tentei passar a ser uma pessoa funcional'. Conclui o segundo grau, comecei a fazer faculdade de psicologia. Eu comecei a responder satisfatoriamente ao programa.

Eu no início relatei que eu 'tô' limpa há 04 anos e eu ingressei com 19 anos. 'A experiência espiritual me aconteceu agora'. Foi um longo processo. Ainda tive recaídas, mas hoje em dia não. A última substância que eu usei foi crack, na linha do trem na 'cracolândia'. Ali eu fiquei desesperada. Até aquele momento eu ainda não havia 'me rendido'. Demorou muito tempo pra eu me render. 'Quando eu me dei por derrotada aí tudo foi diferente'. Aí eu tive um 'despertar espiritual', o meio do desespero. Sou muito grata por estar viva. Me sinto uma pessoa tendo uma segunda chance de vida. Agradeço a coisas que eu não fazia ideia que eram importantes. Eu amo a vida! Ando de bicicleta como se fosse a coisa mais maravilhosa do mundo, e é! $\mathrm{Na}$ 'cracolândia' eu vi gente sem perna, com a perna ferida. A sociedade não vê as 'cracolândias'. São guetos de pessoas que estão morrendo em vida. Agradeço por estar inteira. Me identifico com o 'Kardecismo'. Me sinto um ser humano em evolução. Essa história que nós de NA passamos nos traz uma coisa humana, nos enriqueça humanamente e espiritualmente e que a gente tenha novas chances. Eu gosto de pensar que eu vou ter outras vidas e que nada está sendo em vão. Que existe um plano maior de um Poder Superior e que eu faço parte desta finalidade. 'Eu considero que hoje em dia a minha religião é a gratidão e o meu Poder Superior é a vida!'

\section{Considerações finais}

Narcóticos Anônimos (NA) se define como sendo "uma irmandade ou sociedade de homens e mulheres para quem as drogas se tornaram um problema maior. Somos adictos em 
recuperação, que nos reunimos regularmente para ajudarmos uns aos outros a nos mantermos limpos" (NARCOTICS ANONYMOUS WORLD SERVICES, 2015, p. 11). Assim, percebemos Narcóticos Anônimos como o que se convencionou designar um grupo de 'ajuda mútua', oriundo do programa de recuperação de 12 passos e 12 tradições de Alcoólicos Anônimos.

O conceito de 'doença' de NA é particular. A adição (dependência química) é vista como uma doença física, mental e espiritual. Os membros, então, são motivados a reelaborar os seus padrões de percepção do mundo a partir de um processo de 'encontro consigo mesmo' no grupo. A 'chave terapêutica' para a compreensão do programa de NA passa por 'contar sua história'. O presente, assim, reelabora o passado, não de maneira linear, mas criando um sentido que atua como força catalizadora do sentimento de pertencimento a uma 'nova maneira de viver'. O grupo, nesse sentido, fornece os 'quadros sociais de memória' (HALBWACHS, 1925) necessários a essa reinterpretação do passado. Na entrevista acima, os pontos destacados apresentam diversos momentos em que é possível perceber esta intersecção entre as lembranças da entrevistada e a maneira que estas lembranças são reconstruídas a partir da linguagem própria de Narcóticos Anônimos.

[...] interessa-me enfatizar a percepção de Halbwachs de que a memória não é e não pode ser considerada o ponto de partida, porque ela nunca parte do vazio; a memória é adquirida à medida que o indivíduo toma como sua as lembranças do grupo com o qual se relaciona: há um processo de apropriação de representações coletivas por parte do indivíduo em interação com outros indivíduos (SANTOS, 1998, p. 161).

Nos passos 04 e 05 os membros são incentivados a redigir um 'profundo e destemido inventário moral'. Nele, entram em contato com todas as 'insanidades', como relatou a nossa entrevistada. Essas 'insanidades' que deixam marcas e causam traumas, aqui, não são silenciadas, mas contadas e recontadas num processo perene de 'cura', uma vez que nesta visão a adição é uma doença 'incurável e fatal'. O trauma assim, atua como fator gerador de uma identidade comum. Ao iniciar as reuniões, os membros se identificam da seguinte forma: 'boa noite, meu nome é fulano, adicto em recuperação'. A categoria 'adicto em recuperação', reinventa a identidade do indivíduo, que passa a se perceber como membro de uma 'comunidade afetiva' (HALBWACHS, 1968).

Portanto, a memória traumática nos grupos de Narcóticos Anônimos, funciona como uma 'ferramenta terapêutica', reelaborando o passado através do presente e da força do grupo, combinando elementos tradicionais e modernos. Assim, para Narcóticos Anônimos, o ‘remédio’ é a palavra! 
Agradecimentos: Gostaria de registrar os meus sinceros agradecimentos a todos os que concordaram em conversar conosco, numa experiência que, para além da pesquisa propriamente dita, nos enriqueceu pessoalmente. Aos milhares de membros de Narcóticos Anônimos espalhados pelo Brasil e pelo mundo, o nosso muito obrigado.

\section{REFERÊNCIAS}

BURROUGHS, William S. Junky: drogado. São Paulo: Companhia das Letras, 2013.

HALBWACHS, Maurice. Les cadres sociaux de la mémoire. Paris: F. Alcan, 1925.

HALBWACHS, Maurice. La mémoire collective. Paris: Presses Universitaires de France, 1968.

HARTMAN, Geoffrey H. Holocausto, testemunho e trauma. In: NESTROVSKi, A.; SELIGMANN-SILVA, M. (Orgs.) Catástrofe e Representação. São Paulo: Escuta. p. $207-$ $235,2000$.

NARCOTICS ANONYMOUS WORLD SERVICES. Bem-Vindo a Narcóticos Anônimos. IP n. 22. Traduzido e impresso por Narcotics Anonymous World Services, Inc. 1993. Disponível em: www.na.org/admin/include/spaw2/uploads/pdf/ips/br/PB3122.pdf. Acesso em: 20 abr. 2019.

NARCOTICS ANONYMOUS WORLD SERVICES. Miracles Happens. The Birth of Narcotics Anonymous in Words and Pictures. Chatsworth, California. Traduzido e impresso por Narcotics Anonymous World Services, 2002.

NARCOTICS ANONYMOUS WORLD SERVICES. Texto básico de narcóticos anônimos. Traduzido e impresso por Narcotics Anonymous World Services, Inc. 2015.

ORGANIZAÇÃO MUNDIAL DE SAÚDE: Classificação de Transtornos Mentais e de Comportamento da CID-10: Descrições Clínicas e Diretrizes Diagnósticas. Tradução: Dorgival Caetano, 1. ed. Porto Alegre: Artes Médicas, 1993.

POLLAK, Michael. Memória, Esquecimento, Silêncio. Estudos Históricos, v. 2, n. 3, 1989, p. 3-15. Disponível em:

http://www.uel.br/cch/cdph/arqtxt/Memoria_esquecimento_silencio.pdf. Acesso em: 19 abril 2019.

RAMBO, Lewis R. Understanding Religious Conversion. Ed. Yale University, 1993.

SANTOS, Myrian. Sobre a autonomia das novas identidades coletivas: alguns problemas teóricos. Revista Brasileira de Ciências Sociais, v. 13, n. 38, p. 151-165, out. 1998.

Disponível em http://www.scielo.br/scielo.php?script=sci_arttext\&pid=S010269091998000300010. Acesso em: 20 abr. 2019. 
SANTOS, Myrian; ARAÚJO, Maria Paula Nascimento. História, memória e esquecimento: Implicações políticas. Revista Crítica de Ciências Sociais, n. 79, p. 95-111, dez. 2007. Disponível em https://www.ces.uc.pt/publicacoes/rccs/artigos/79/RCCS79-095-111MPNascimento-MSepulveda.pdf. Acesso em: 19 abr. 2019.

SANTOS, Myrian. (2013). Memória coletiva, trauma e cultura: um debate. Revista USP, $\mathrm{n}$. 98, p. 51-68, ago. 2013. Disponível em: https://doi.org/10.11606/issn.2316-9036.v0i98p5168. Acesso em: 20 abr. 2019.

SELIGMANN-SILVA, Marcio. 2000. A história como trauma. In: NESTROVSKI, A.; SELIGMANN-SILVA, Márcio. (Orgs.). In: Catástrofe e Representação. São Paulo: Escuta, p. 73-98, 2000.

\section{Como referenciar este artigo}

SILVA, Rodrigo Ferreira. Memória, trauma e identidade: trajetórias na Irmandade de Narcóticos Anônimos. Rev. Sem Aspas, Araraquara, v. 8, n. 1, p. 74-87, jan./jun. 2019. ISSN: 2358-4238. DOI: 10.29373/sas.v8i1.12476.

Submetido em: 22/04/2019

Aprovado em: 25/06/2019 